\title{
Seasonal timing and recurrence of methyl jasmonate treatment influence pine weevil damage to Norway spruce seedlings
}

\author{
Yayuan Chen ${ }^{1}$ (D) Helena Bylund ${ }^{1} \cdot$ Christer Björkman $^{1} \cdot$ Frauke Fedderwitz $^{1,2}$. \\ Adriana Puentes ${ }^{1}$
}

Received: 19 December 2019 / Accepted: 13 July 2020 / Published online: 23 July 2020

(C) The Author(s) 2020

\begin{abstract}
Defense can be induced in conifer seedlings to reduce pine weevil (Hylobius abietis) damage, by treatment with the plant hormone methyl jasmonate (MJ). Few studies have addressed important practical issues regarding the use of MJ such as treatment incidence and timing, seedling age and its compatibility with plant nursery practices. We examined if levels of pine weevil damage depend on seasonal timing and recurrence of MJ treatment, and if the observed effects depend on plant age. Norway spruce (Picea abies) seedlings from two age cohorts (1 year and 1.5 years old) received four MJ treatments: MJ application before winter storage in the previous year, after winter storage but before spring/summer planting, repeated MJ application (both before winter storage, and before planting) or no MJ application at all. Pine weevil damage was evaluated in a lab and field experiment. We found that the timing and recurrence of MJ treatment affected the amount of damage inflicted by pine weevils in different ways, but these effects were consistent among age cohorts. MJ application before winter storage provided the most effective protection, and this reduction in damage was comparable to that provided by a currently used physical protection method against pine weevil feeding. Our results indicated that MJ can be applied in line with nursery practices (before winter storage) and provides adequate protection for two growing seasons.
\end{abstract}

Keywords Conifer seedlings · Forest plant protection · Hylobius abietis · Induced defense · Nursery protocols

Electronic supplementary material The online version of this article (https://doi.org/10.1007/s1105 6-020-09803-4) contains supplementary material, which is available to authorized users.

Yayuan Chen

yayuan.chen@slu.se

1 Department of Ecology, Swedish University of Agricultural Sciences (SLU), Box 7044, SE-75007 Uppsala, Sweden

2 Present Address: Teagasc, Crop Research Centre, Oak Park, Carlow R93 XE12, Ireland 


\section{Introduction}

Insects are one of the major agents of damage to European forests (Matyjaszczyk et al. 2019). The problems caused by insects are usually more prominent in clear-cut forests as they are often regenerated through planting, and the seedlings are susceptible to insect herbivory during establishment. In these newly planted forests, the pine weevil (Hylobius abietis) is one of the most destructive insect pests because it consumes the stem cambium, often girdling seedlings (entire ring of bark removed), causing high levels of plant mortality (Hagner and Jonsson 1995; Långström and Day 2007). Protective measures against pine weevil damage are necessary to prevent up to $100 \%$ mortality and to date, insecticide treatment has been one of the most prevalent methods in Northern Europe (Eidmann et al. 1996; Nordlander et al. 2011; Örlander and Nilsson 1999; Von Sydow 1997). However, the use of insecticides in forest pest insect management is being phased out due to environmental and human health issues. Even though various silvicultural practices and physical protective methods against the pine weevil are available, their effects are variable depending on site conditions (Nordlander et al. 2011; Wallertz et al. 2018; López-Villamor et al. 2019); thus, complementary and sustainable methods of seedling protection are needed.

One potential strategy to reduce forest pest damage, which has received less attention, is to amplify the plant's own defenses. These defenses encompass resistance traits that enable plants to prevent, stop or reduce damage inflicted by insects, and tolerance traits that enable withstanding and recovering from damage. Defenses can be classified into two categories: (1) constitutive defenses which are present at all times, and (2) induced defenses which are activated immediately when damage occurs (inducible defenses), or activated under subsequent attacks after perceiving initial cues or stimuli relevant to a specific type of attack (priming of defense) (Mageroy et al. 2020; Wilkinson et al. 2019). Induced defenses, in particular, have been shown to be effective at reducing damage by aphids, spider mites, thrips and other insect pests, in crops such as grape, strawberry, tomato, soybean and lima bean (Choh et al. 2004; Omer et al. 2000; Thaler et al. 2001; Selig et al. 2016; Warabieda et al. 2005). These effects have been achieved by triggering defenses prior to insect attack, without causing physical damage, through the use of the plant hormone methyl jasmonate (MJ). MJ is the volatile counterpart of jasmonic acid (JA), which regulates plant responses to abiotic and biotic stresses, especially those involved in mediating insect induced resistance (Kahl et al. 2000; McConn et al. 1997; Miller et al. 2005). Application of MJ activates production of plant defensive compounds and expression of resistance-related genes, subsequently reducing insect herbivory (Yu et al. 2019). Thus, utilizing MJ-induced defenses has emerged as an effective method to increase plant protection against various crop pests (Stella de Freitas et al. 2019; Stenberg 2017).

In forest pest insect management, there has been less focus on the effects of exogenous MJ treatment on coniferous seedlings and the possibility of using it as a tool to boost forest regeneration. This is despite documented increases in the total amount of defensive compounds like terpenes, phenolic compounds and resin following MJ treatment in different coniferous species, including Picea abies (Heijari et al. 2005; Hudgins et al. 2004; Moreira et al. 2009; Zas et al. 2014). Changes in these chemical traits are known to be effective induced defense responses following stem damage or biotic attack (Franceschi et al. 2005; Hudgins et al. 2004). Furthermore, these MJ-induced changes not only occur locally but also systemically throughout the plant (Huber et al. 2005; Moreira et al. 2009). MJ treatment to coniferous seedlings has been shown to affect pine weevil feeding behaviour, resulting in an overall reduction 
in damage levels and the likelihood of girdling relative to untreated plants (Moreira et al. 2009; Fedderwitz et al. 2015). Moreover, these plant protective effects have been observed both in the lab and field. Field results from a previous study showed that MJmediated protection remained for two growing seasons after the initial treatment (Zas et al. 2014).

Besides the enhanced protective effects, it has been shown that MJ can negatively affect plant growth following application (Heijari et al. 2005; Gould et al. 2009). When defenses are triggered by MJ, resources could be allocated to synthesize defensive compounds and diverted away from growth. However, this growth reduction is not necessarily a hindrance for using MJ to protect conifer seedlings. In fact, a recent study shows that this short term growth reduction could be exploited by plant nurseries to stop growth when seedlings reach a certain height (Fedderwitz et al. 2019). In the long term, MJ treated seedlings can compensate the growth loss and this temporary reduction is compensated by lower mortality compared to untreated seedlings (Gould et al. 2008; Zas et al. 2014). Thus, MJ has the potential to emerge as a non-pesticide approach for conifer seedling plant protection.

Before MJ can be implemented as a practical protection tool, several aspects need to be further investigated in order to optimize its effects. First, the level of induced defense triggered by $\mathrm{MJ}$ is dose dependent but the required amounts to reach the desired defensive effect can vary among species and with different plant variables. For instance, higher concentrations of MJ can lead to stronger defensive responses and older plants can withstand higher concentrations (Zeneli et al. 2006; Heijari et al. 2008), while overdose can be phytotoxic or even lethal for younger plants (Gould et al. 2009). Second, the timing of induction is another crucial factor. Plant responses occur within minutes after JA accumulation (Koo et al. 2009), but it takes longer until induced defenses become effective at reducing herbivory (Karban 2011). So far, studies examining the efficacy of MJ against pine weevil damage have conducted the treatment a few days or weeks prior to insect exposure. However, if MJ treatment is to be implemented in nurseries, it should ideally be compatible with conifer seedling production practices. Briefly, these practices involve sowing of seeds in spring with plants being allowed to grow until late autumn; they are then packaged and stored in freezer rooms until the following spring/summer when they are planted. Treatment with MJ could, thus, potentially be conducted before winter storage or before planting, or even at both time points. Currently, we lack knowledge on whether differences in timing and recurrence of treatment, as well as seedling age, could affect the protective effects of MJ against pine weevil damage. Therefore, we conducted a lab and a field experiment using Norway spruce seedlings to answer the following questions:

(1) If MJ treatment is applied on one occasion, do seedlings receive similar amounts of pine weevil damage regardless of whether seedlings are treated before winter storage or before planting?

(2) If MJ treatment is applied recurrently over 2 years, both before winter storage (in autumn) and before planting (in spring/summer), does it result in less pine weevil damage compared to when MJ treatment is applied on only one occasion?

(3) Are the effects of recurrent application and timing of the MJ treatment also affected by the age of the seedlings, i.e. older seedlings that were sown earlier ( 1.5 years old) or younger seedlings sown later (1 year old)? 


\section{Materials and Methods}

\section{Plant material}

All the Norway spruce seedlings used in the experiments were obtained from a commercial plant nursery (Bergvik Skog Plantor AB, Nässja) in Sweden. Half of the seedlings were from seeds sown in July 2015 (hereafter referred to as S2015 or the older cohort, Fig. 1) and overwintered outdoors in their first year. The other half of the seedlings were from seeds sown in April 2016 (hereafter referred to as S2016 or the younger cohort, Fig. 1). This plant material was originally part of a separate experiment that examined the growth of MJ-treated Norway spruce seedlings with that of untreated and long-night treated seedlings (Fedderwitz et al. 2019). Hence, we describe the initial MJ treatments related to the previous study in the paragraph below, but the follow-up treatments associated with the present study are described in the next section.

In July to August 2016, half of the seedling from the S2015 cohort were sprayed with $10 \mathrm{mM}$ MJ (Sigma-Aldrich 95\%, Ref. No. 392707) three times, and the interval between sprayings was 1 week. The other half of the seedlings (control group) in the S2015 cohort

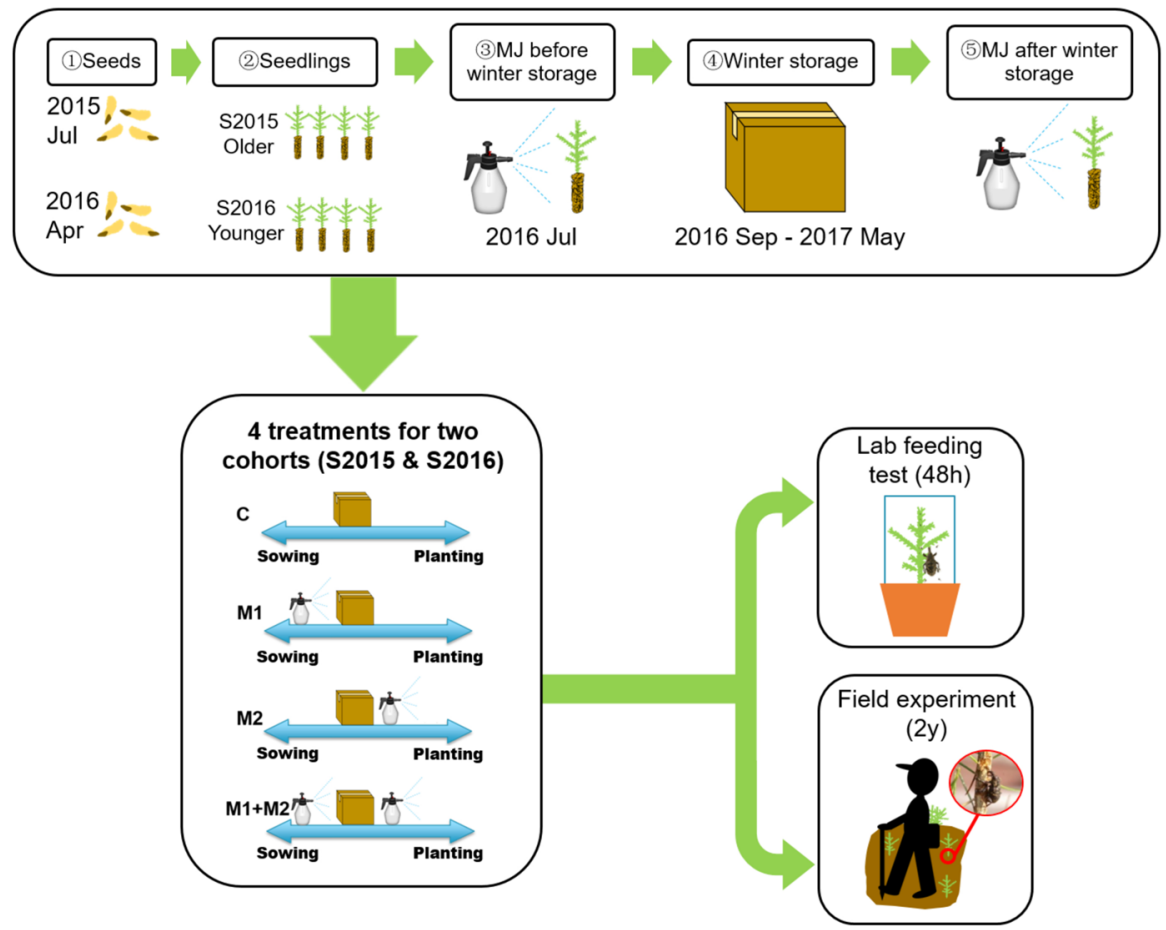

Fig. 1 Experimental design showing the timing of treatments relative to seed sowing and plant nursery operations. First, seeds of Norway spruce (Picea abies) were sown in July 2015 (S2015) or April 2016 (S2016) and allowed to grow until the autumn of 2017 (steps 1 and 2). Methyl jasmonate (MJ) was applied before or after winter storage (steps 3 to 5), or at both time points. Seedlings from each age cohort (S2015 and S2016) were subjected to four different treatments: MJ treatment before winter storage or before summer planting (M1 and M2, respectively), repeated MJ treatment both before storage and before planting (M1 + M2), and no MJ application at all (C). Plants were then assigned to a laboratory non-choice pine weevil (Hylobius abietis) feeding experiment or planted in a forest clear-cut and evaluated over 2 years 
were sprayed with carrier solution (solution of $2.5 \%$ ethanol, v:v) with the same frequency. The seedlings in the S2016 cohort were treated in the same way and at the same time, as the S2015 cohort. All the treatments were performed outdoors and plants were kept growing outside until September 9, 2016 when they were subjected to a long night treatment (13 h darkness every day from 19:00 to 8:00) for 4.5 weeks. The long night treatment is a nursery practice used to prepare seedlings for winter storage and stop seedling growth at a desired height. After this treatment, all seedlings were packed in sealed boxes and stored in a freezer $\left(-5{ }^{\circ} \mathrm{C}\right)$ over the winter. For the current study (Fig. 1), we used 200 seedlings from each age cohort (S2015 and S2016) and each treatment group (MJ-treated and control group).

\section{Methyl jasmonate treatments}

At the end of May 2017, seedlings described in the previous section were delivered from the nursery to our department (Swedish University of Agricultural Sciences, Uppsala, Sweden) and thawed at $5{ }^{\circ} \mathrm{C}$. A week later, seedlings for the lab experiment were planted in plastic pots and seedlings for the field experiment were placed in seedling trays. These seedlings were then kept under greenhouse conditions for later use. The light period was $16 \mathrm{~h}$ ( $8 \mathrm{~h}$ dark) in the greenhouse, and day/night temperature was $20 / 16 \mathrm{C}^{\circ}$. In order to test if the efficacy of MJ depends on whether treatments are conducted solely in 1 year or consecutively over 2 years, half of the previously MJ-treated seedlings from the S2015 cohort were sprayed with deionized water (treatment M1; MJ application before storage) and the other half with $10 \mathrm{mM}$ MJ mixed with carrier solution (treatment M1 + M2; two MJ applications: before storage and before planting). For the remaining non-MJ-treated seedlings in the S2015 cohort, half of them were treated once with $10 \mathrm{mM}$ MJ mixed with carrier solution (treatment M2; MJ application before planting), and the other half were sprayed once with deionized water (treatment $\mathrm{C}$; control: no $\mathrm{MJ}$ applications at either time point). The same treatments were repeated on the S2016 seedling cohort (Fig. 1).

All treatments were performed only once on June 9, 2017 in a laboratory fumehood. MJ (Sigma-Aldrich 95\%, Ref. No. 392707) was mixed with a carrier solution of $2.5 \%$ (v:v) ethanol to achieve the $10 \mathrm{mM}$ concentration before spraying. The spray bottle was always pumped until the inner air pressure reached its limit of $2.5 \mathrm{bar}$, and shaken vigorously so that the MJ and carrier solution were well-mixed before spraying. The spray container was a Free-Syringe PC 1.5 litre plastic bottle (Jape Products AB, Hässleholm, Sweden). The nozzle was placed about $40 \mathrm{~cm}$ away from the plants and spraying was conducted so that the solution reached and covered the entire seedling in each pot. Each seedling was sprayed approximately for one second, then the pot was turned around 180 degrees and the spraying was repeated in the same way. Treatment of plants with deionized water was performed the same way as MJ treatment. The seedlings treated with MJ were dried at room temperature (inside a fumehood, light period $16 \mathrm{~h}$ ) during $24 \mathrm{~h}$, before they were moved back in the greenhouse together with other seedlings.

\section{Lab experiment}

\section{Pine weevils}

For the lab experiment, the pine weevils used in the feeding test were collected during their spring migration on May 27, 2017 at a sawmill (Balungstrands Sågverk AB) in 
Enviken, Sweden. They were kept in darkness at a room temperature of $10{ }^{\circ} \mathrm{C}$ and fed with young Scots pine (Pinus sylvestris) stems and branches. One week before the feeding tests on June 16, 2017, pine weevils were placed at room temperature for acclimatization (light-dark cycle, $16 \mathrm{~h}-8 \mathrm{~h}$ ) and supplied with water and Scots pine branches. Female pine weevils were individually placed in a Petri dish with a small Scots pine branch piece for $24 \mathrm{~h}$. Those that fed on the branch during this period were selected and starved for 3 days before the feeding test.

\section{Testing resistance against the pine weevil}

In order to test how the timing and recurrence of MJ treatments on seedlings of two age cohorts affects pine weevil feeding under non-choice conditions, we conducted feeding tests in the lab (Fig. 1). Two weeks after the MJ treatment on June 22 and 24, 2017, 96 seedlings were exposed to pine weevils (12 seedlings for each treatment). Feeding tests were conducted in two rounds, one right after the other, due to limited space in the lab. Each pot containing one seedling was covered with a transparent plastic cylinder with a mesh opening at the top, and one female pine weevil was placed inside for $48 \mathrm{~h}$. After the feeding test, absolute stem area debarked was calculated for each plant by using millimetre paper to measure the length and width of each scar, and adding up all the areas for each scar.

\section{Seedling growth measurements}

The height and diameter of seedlings were measured in the greenhouse to quantify and compare growth trajectories of MJ-treated and non-MJ treated plants. Five individuals from each treatment group were set aside for these growth measurements. The measurements began on June 8, 2017 and ended on September 10, 2017, with an interval of 6-11 days between measurements. A total of 10 measurements were taken.

\section{Field experiment}

To investigate how the timing and recurrence of MJ treatment affects pine weevil preference under field conditions, we set up an experiment in a 1-year-old clear-cut with sandy soil near Tierp, central Sweden $\left(60^{\circ} 21^{\prime} \mathrm{N}, 17^{\circ} 26^{\prime} \mathrm{E}\right)$. The field was previously a commercial forest dominated by Scots pine and harvest was conducted in March 2016. A total of 330 seedlings were planted in 33 blocks on June 15, 2017. Each block was a rectangular patch (about $50 \mathrm{~cm} \times 300 \mathrm{~cm}$ ) that was previously scarified with an excavator before planting in 2017. Ten seedlings were planted in random order along the two long sides ( 5 seedlings per side) at the border between the humus and mineral soil. The eight treatment combinations (MJ $\times$ seedling cohort) were replicated once in each block, and an extra seedling treated with the commercial protection Conniflex ${ }^{\circledR}$ (physical barrier) from each cohort, was also included. Conniflex is a sand-glue mixture that covers the stem to physically protect seedlings from stem chewing by the pine weevils. It has been shown to efficiently reduce pine weevil damage and enhance seedling survival (Nordlander et al. 2009). Since such physical barriers are often used and have a well-established protective effect, we included it as a positive control in the field experiment to compare against the efficiency of $\mathrm{MJ}$ in reducing pine weevil damage. 


\section{Assessment of pine weevil damage}

Pine weevil damage was assessed at two occasions, across two growing seasons (Fig. 1). The first measurements were done on September 21, 2017 to assess early pine weevil damage and seedling establishment. The second measurements were conducted the following year on June 28, 2018 to examine seedling survival over the winter and follow the development of pine weevil damage. During the assessments, we measured the following damage variables: (1) $\mathrm{H}_{\text {damage }}$ - the height from the ground (right above the root collar) to the upper side of the highest and last pine weevil feeding scar found on the stem; (2) $\mathrm{P}_{\text {damage }}$ - the estimated proportion of stem area damaged in relation to the total surface area up to the $\mathrm{H}_{\text {damage }}$ described in (1). Eight replicates of each treatment from 33 blocks were randomly chosen to calculate the mean diameter (D) of plants. Using the above mentioned measurements and the equation for calculating the circumference of a circle (estimated perimeter of the seedling stem), we estimated the debarked area $\left(\mathrm{mm}^{2}\right)$ for each plant as: $A_{\text {debarked }}=(\pi \cdot \mathrm{D})$ $\mathrm{H}_{\text {damage }} \cdot \mathrm{P}_{\text {damage }}$. This method was used if the feeding scars were scattered and irregularly shaped. If the feeding scars were few and small, absolute stem area debarked by pine weevils was calculated by measuring the length and width of each scar with a ruler, and adding up the areas if more than one scar was found. In addition, the height of living seedlings, the frequency of pine weevil attack, as well as the number of dead seedlings and the possible cause of death were recorded. We categorized seedlings according to three possible causes of mortality: Drought - seedlings which appeared to have dried out but showed no evidence of pine weevil girdling; Girdled - seedlings which were girdled by pine weevil feeding; Other - seedlings which were dead due to other unknown cause (e.g., pulled out from the soil by birds or mammals in the area).

\section{Statistical analysis}

All analyses were conducted in R software version 3.5.2 (R Core team, 2018) using R studio 1.1.463 (RStudio team 2016), and all graphs were plotted using the ggplot2 package (Wickham 2016). For the lab experiment, a linear model ( $l m$ command from the nnet package, Venables and Ripley 2002) was used to test the effect of MJ treatments, conducted at different times and occasions, on levels of pine weevil damage. This model included two fixed effects: treatment (4 levels: C, M1, M2, M1 + M2), age cohort (2 levels: S2015, S2016) and their interaction. Plant diameter before the feeding test was included as a continuous covariate, and the response variable explored was debarked area by pine weevils. Seedling growth (height increment) from greenhouse measurements was also tested with a linear model, including the same fixed effects as the pine weevil damage model. Initial height was added as a covariate in the growth model. For the field experiment, blocks where no pine weevil damage was observed on any of the plants were excluded since these blocks were considered to have no pine weevil pressure. A generalized linear mixed model (glmer command from lme4 package, Bates et al. 2015) including the same fixed factors as for the lab experiment, was fitted for area debarked but it included block as a random factor. In addition to debarked area, attack rate (plant attacked or not) and mortality (alive or dead) in the field were also examined as response variables. A linear mixed model (lmer command from lme4 package, Bates et al. 2015) was used to test the same fixed and random effects as the pine weevil field damage model, but for seedling growth (height increment). To test the significance of fixed effects and their interaction in all models, the Anova command from the car package (Fox and Weisberg 2011) was used. If significant main 
effects were found, Fisher's least significant difference (LSD) tests were conducted among treatment levels with the emmeans command from emmeans package (Lenth 2019). Due to the low number of damaged seedlings, which resulted in many zeros when analysing debarked area and attack rate, different data transformation and distributions were tested. Generalized mixed linear models that provided the best fit of the data were chosen. Even though models converged, no multiple comparisons among treatments followed for some models and we interpreted significance with caution.

\section{Results}

\section{Lab experiment}

There was a significant difference in area debarked by pine weevils among MJ treatments differing in timing and recurrence, but the effect of age and the interaction effect of age and MJ treatment were not significant (Table 1). Multiple comparisons showed that seedlings with treatment only before winter storage (M1) received the least damage and this was significantly lower than for control plants (66.5\% reduction in damage; Fig. 2a, b). Consecutive MJ treatment (M1 + M2) also reduced damage (54.5\% reduction; Fig. 2a, b), while MJ treatment right before planting (M2) had the least effect on pine weevil damage (a statistically non-significant $17.7 \%$ reduction; Fig. $2 \mathrm{a}, \mathrm{b}$ ) compared to the control treatment. This pattern was consistent between age cohorts (Fig. 2a, b).

Seedlings varied significantly in growth (height increment) among treatments and between age cohorts (Table S1). Overall, seedlings treated with MJ experienced a reduction in growth compared to control seedlings, and those from the S2015 cohort grew significantly more in height than those from the S2016 cohort (Fig. 3a and 3b). The height increment of the S2016 cohort was quite similar among MJ treatments (Fig. 3b), while there were significant differences among these treatments in the S2015 cohort (Fig. 3a).

Table 1 Results of Analysis of Variance (ANOVA) (df: degrees of freedom; F: F-value; P: $p$ value) for linear models used to examine differences in stem area debarked (Debarked area, $\mathrm{mm}^{2}$ ) by pine weevils (Hylobius abietis) in a lab feeding test. Models included methyl jasmonate treatments (M1, M2, M1 + M2 and C; see Fig. 1 for an explanation), Norway spruce (Picea abies) seedlings belonging to two age cohorts (Sown in 2015 or 2016), and their interaction. Seedling diameter ( $\mathrm{mm}$ ) was used as a continuous covariate in the model

\begin{tabular}{lccc}
\hline Source of variance & \multicolumn{2}{l}{ Debarked area } & \\
\cline { 2 - 4 } & $\mathrm{df}$ & $\mathrm{F}$ & $\mathrm{P}$ \\
\hline Age cohort & 1 & 1.393 & 0.242 \\
Treatment & 3 & 15.433 & $\mathbf{0 . 0 0 0 1}$ \\
Diameter & 1 & 1.637 & 0.205 \\
Treatment $\times$ Age cohort & $3 \times 1$ & 1.253 & 0.297 \\
\hline
\end{tabular}

Statistically signficant effects are shown in bold $(\mathrm{P}<0.05)$ 


\section{a Lab feeding test S2015}

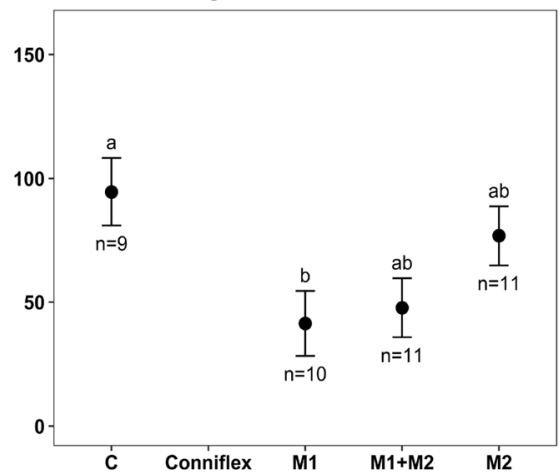

C First field assessment S2015

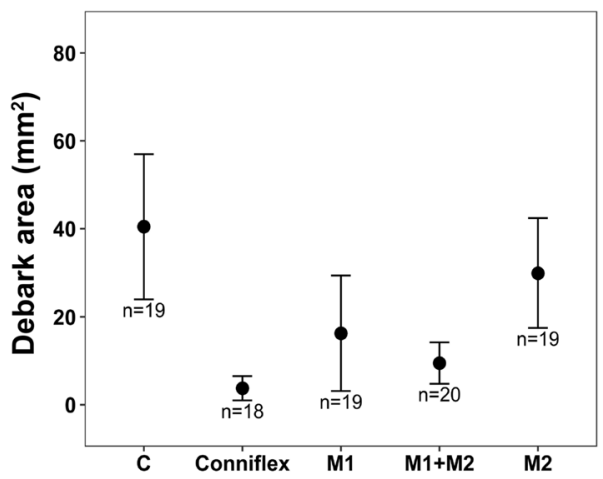

e Second field assessment S2015

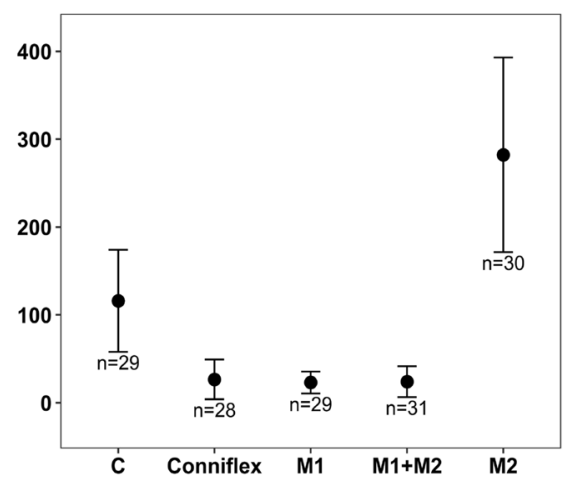

b Lab feeding test S2016

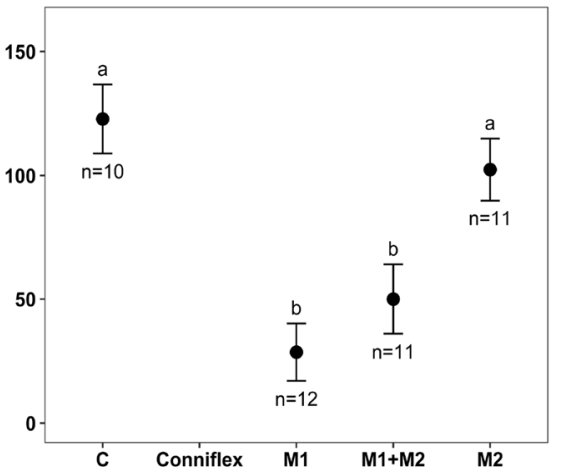

d First field assessment $\mathbf{2 0 1 6}$

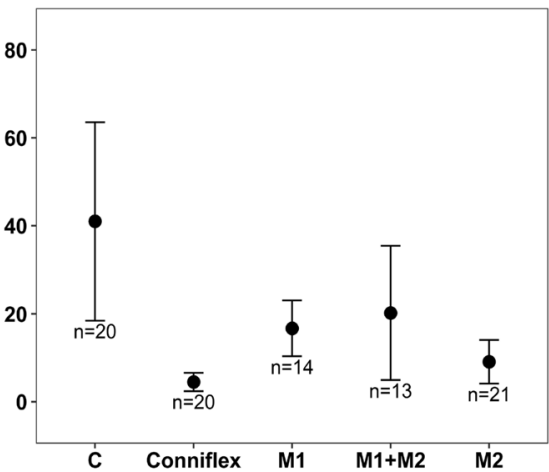

f Second field assessment S2016

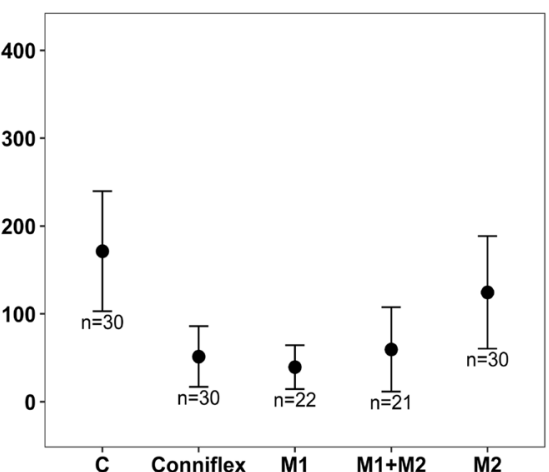

Fig. 2 Mean stem debarked area $\left(\mathrm{mm}^{2}\right)( \pm$ standard error) by pine weevils (Hylobius abietis) for Norway spruce (Picea abies) seedlings belonging to two age cohorts sown in 2015 (S2015; panels a, c and e) or in 2016 (S2016; panels b, d and f). For each cohort, results are presented per experimental treatment in the lab (panels a and b) and field (panels c and d, first assessment of damage in Sept. 2017; panels e and f, second assessment of damage in June 2018). Seedlings were treated with methyl jasmonate (MJ) before winter storage (M1), after (M2), or both before and after $(\mathrm{M} 1+\mathrm{M} 2)$; controls $(\mathrm{C})$ received no MJ application at all (see Fig. 1). Seedlings with the physical barrier Conniflex were included as positive controls in the field experiment only. Different letters indicate significant differences among treatments at the 5\% level (TukeyKramer tests), while means without letters are from models which converged but did not allow multiple comparisons (See Statistical analyses). Sample sizes (n) varied as some seedlings died during the experiment 
a

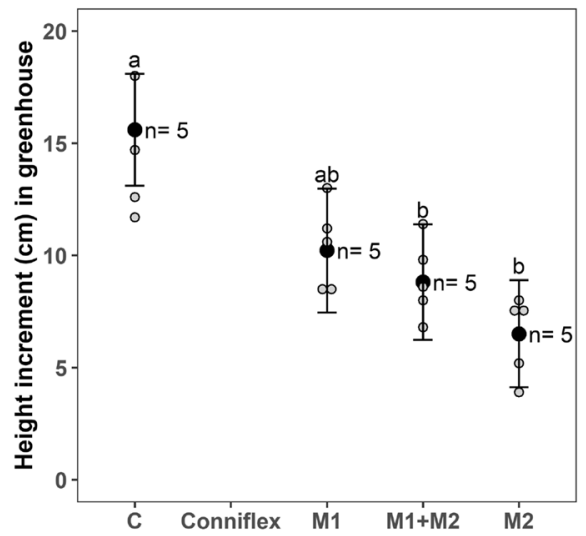

C

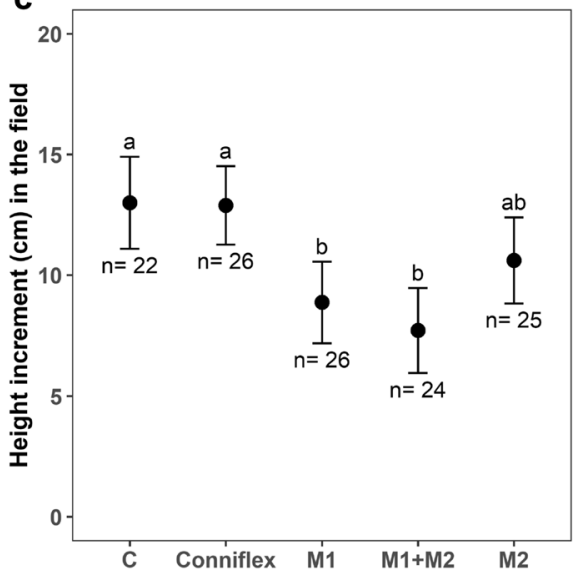

b

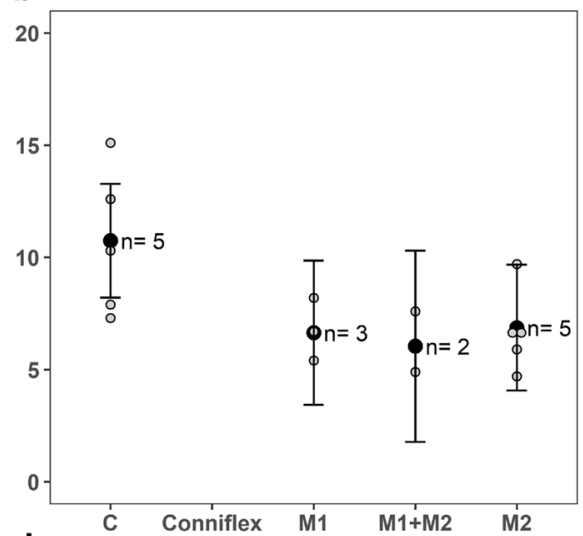

d

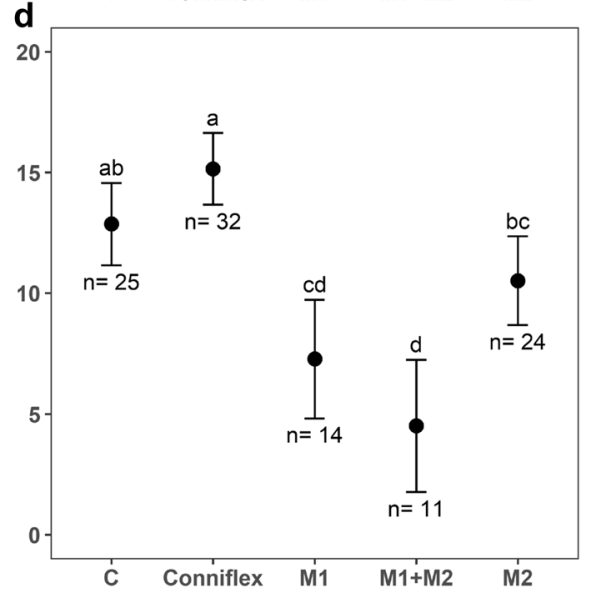

Fig. 3 Mean seedling height increment (final height subtracted with initial height, $\mathrm{cm}, \pm 95 \%$ confidence intervals) of Norway spruce (Picea abies) seedlings belonging to two age cohorts sown in 2015 (S2015; panels a, and c) or in 2016 (S2016; panels b, and d). Plants were grown in a greenhouse for 95 days (panels $a$ and b, actual data points in faint grey) or in the field between the time of planting (June 2017) until the second field assessment (June 2018) (panels c and d). Seedlings were treated with methyl jasmonate (MJ) before winter storage (M1), after (M2), or both before and after (M1+M2); controls (C) received no MJ application at all (see Fig. 1). Seedlings with the physical barrier Conniflex were included as positive controls in the field experiment only. Different letters indicate significant differences among treatments that were significantly different at the $5 \%$ level (Tukey-Kramer tests). Significant letters are missing in panel $b$ as some treatments had too few replicates for conducting such comparisons. Sample sizes (n) vary as some seedlings died during the measurement period

\section{Field experiment}

Similar to the lab experiment, we found that the timing and recurrence of MJ treatment significantly affected the amount of damage inflicted by pine weevils. By the first field assessment, which was 3 months after planting, pine weevils had damaged 44 seedlings $(22.0 \%)$ in total, across 20 out of the 33 blocks. The attack rate was not significantly different among treatments and age cohorts, or their interaction (Table 2). With respect to pine weevil damage, we found significant differences in debarked area between the two age cohorts 


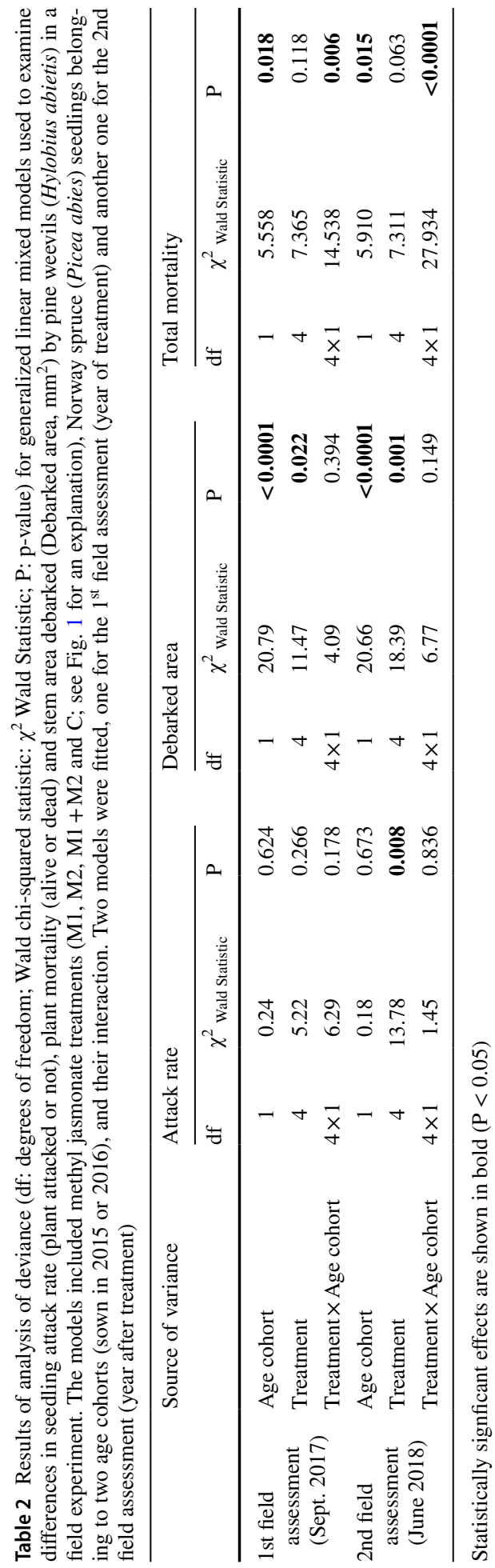


and among treatments (Table 2). Overall, MJ-treated seedlings received less damage than control seedlings (58.4\% less damage; Fig. 2c, 2d). Seedlings with the physical barrier (Conniflex), which were included as a positive control, received the least damage $(89.9 \%$ less than control; Fig. 2c, 2d). With regards to seedling age, the S2015 cohort as a whole received significantly more pine weevil damage than the S2016 cohort. Seedling mortality was mostly attributed to drought and girdling, while other causes were less common. The overall mortality of seedlings was significantly lower for the S2015 cohort (Table 2), while MJ treatment before storage (M1) and those treated consecutively (M1 + M2) for the S2016 cohort showed higher drought mortality compared to the other treatments (Fig. 4a, 4b).

By the second damage assessment, which was 1 year after planting, pine weevils had damaged 80 seedlings (26.7\%) in total, across 30 out of 33 blocks. The attack rate was significantly different among treatments, but not between age cohorts or the interaction of treatment and age cohort (Table 2). Seedlings with the physical barrier (Conniflex) were less frequently attacked, while attack rate was similar among seedlings receiving MJ treatment (Table S2). With respect to pine weevil damage (area debarked), we found a similar pattern to that found in the lab experiment (Fig. 2a, 2b, 2e, 2f). The main effects of
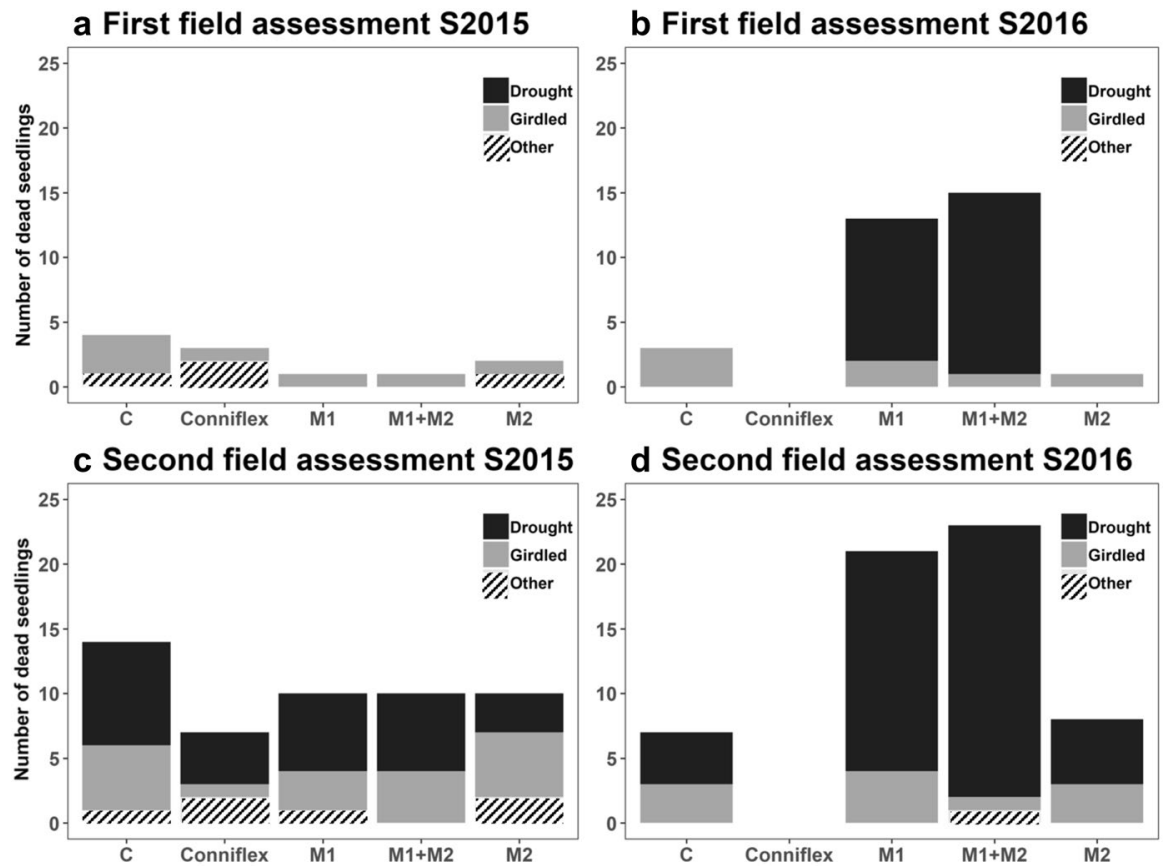

Fig. 4 Mortality (number of dead seedlings) of Norway spruce (Picea abies) seedlings belonging to two age cohorts (sown in 2015 or 2016) during two field assessments of pine weevil damage. A total of 33 seedlings for each treatment and age cohort (S2015: panels a and c; S2016: panels b and d) were planted in the field (panels a and b, first assessment of damage in Sept. 2017; panels c and d, second assessment of damage in June 2018). Seedlings were treated with methyl jasmonate (MJ) before winter storage (M1), after (M2), or both before and after (M1 + M2), controls (C) received no MJ application at all (see Fig. 1). Seedlings with the physical barrier Conniflex were included as positive controls. We categorized plants according to several possible causes of death: "Drought" included dead seedlings that appeared to have dried out but showed no signs of girdling; "Girdled" included dead seedlings for which an entire ring of barked had been removed by pine weevil feeding; "Other" included dead seedlings which died due other unknown reasons 
treatment and age cohort on damage levels were significant (Table 2), and the overall pine weevil damage level for the S2015 cohort was significantly higher than that for the S2016 cohort. As in the lab experiment, seedlings with MJ treatment before winter storage (M1) received the least damage (78.6\% less than control), and those with $\mathrm{MJ}$ treatment right before planting (M2) received the most damage (43.1\% less than control) among all MJ treatments (Fig. 2e, 2f). We also found that the total mortality of seedlings almost doubled compared to what we observed during the first assessment, and the interaction of treatment and age was significant (Table 2). More girdled seedlings were found for the S2015 than the S2016 cohort, while higher mortality attributed to drought was observed for the S2016 cohort. This is mainly due to the high drought mortality of S2016 seedlings in the treatments M1 (MJ before winter storage treatment) and M1 + M2 (MJ treatment twice; before winter storage and before planting).

Seedling growth patterns in the field showed some similarity to those observed in the greenhouse. The height increment in the field was significantly affected by treatment, the interaction of treatment and age cohort, as well as initial height (Table S1). The height increment in the field showed similar patterns between the two age cohorts (Fig. 3c, 3d). For MJ treated plants, the height increment of the seedlings with MJ treatment only before planting (M2) eventually reached the same level as that of control seedlings, while the other two treatments (M1 + M2 and M2) still grew significantly less than control seedlings (Fig. 3c, 3d).

\section{Discussion}

Overall, our results show that MJ treatment reduces pine weevil damage and that the protective effects vary with the timing and recurrence of treatment, but not with the seedling age cohort. To our knowledge, this is the first study that has examined how an almost 1-year-long ( 10 months) gap between MJ treatments can affect protection against pine weevil damage in Norway spruce seedlings. Our results show that a reduction in damage, comparable to that provided by currently used countermeasures such as physical barriers, can be achieved if MJ treatment is implemented at the right timing. Seedlings receiving MJ treatment before nursery winter storage the previous year, were least damaged by pine weevils both in lab and field. Recurrent treatment did not provide greater protection compared to treatments conducted at one occasion. We conclude that MJ treatment can be practically implemented in line with nursery practices and seedlings of different ages, below we discuss our findings in more detail.

Nearly all MJ treated seedlings in both lab and field experiments showed reduced pine weevil damage in terms of debarked area compared to control plants. This result is consistent with other studies that have used MJ to trigger induced defenses in seedlings of the same and other coniferous species (Moreira et al. 2009; Sampedro et al. 2010; Zas et al. 2014; Fedderwitz et al. 2015). The reduction in damage has been shown to be mediated, in part, by changes in feeding behaviour. For instance, pine weevils make fewer and smaller feeding scars on MJ treated Norway spruce seedlings compared to non-treated seedlings (Fedderwitz et al. 2015). Studies have also found that MJ-treated conifer seedlings have a lower risk of being girdled and this could be related to changes in the continuation (or not) of feeding by the pine weevils (Zas et al. 2014; Fedderwitz et al. 2015). Our results, thus, 
corroborate previous findings that $\mathrm{MJ}$ treatment can enhance seedling resistance against this insect pest.

However, the extent of damage reduction depends on the timing and recurrence of treatment. Our results indicated that MJ application before winter storage is the best timing for conducting treatment, as it offered the best protection to seedlings. A previous study testing MJ treatment at one and two occasions found that recurrent treatment provided better protection against pine weevils than single treatment (Zas et al. 2014). These results were in contrast to our study; however, they used a shorter time lag between their recurrent treatments ( 4 and 2 weeks before exposure to pine weevils). We found that consecutive MJ treatment across years was not necessary, as it did not result in a greater reduction of pine weevil damage than the MJ treatment conducted before storage. Similarly, another study did not find greater resistance to the pathogen Diplodia pinea when MJ treatment was repeated (Gould et al. 2009). Our results suggest that to enhance and maintain seedling resistance against pine weevil feeding, MJ application does not need to be recurrent or conducted right before exposure to this insect pest. Thus, our results may increase the potential of introducing MJ as plant protection tool in nurseries.

It is important to note that in our study, treatments with different timing and recurrences resulted in different doses of $\mathrm{MJ}$, which could contribute to variation in its protective efficacy. The dose of MJ can be manipulated by either using the same concentration but different frequencies (or volumes) of spraying, or different concentrations but the same frequency (or volume) of spraying. Studies involving different MJ concentration but the same frequency of spraying, have shown that higher concentration triggers stronger induced chemical responses, with seedlings subsequently receiving less pine weevil damage (Moreira et al. 2009; Zas et al. 2014). Using the same concentration but repeated MJ treatment, also results in higher production of defensive chemical compounds and less pine weevil damage (Zas et al. 2014). In our study, treatments did not differ in concentration but resulted in different doses of $\mathrm{MJ}$ with respect to total volume of $\mathrm{MJ}$ (highest to lowest volume: $\mathrm{M} 1+\mathrm{M} 2>\mathrm{M} 1>\mathrm{M} 2$ ). In line with previous studies, the treatment with the lowest dose (M2, 1 spraying) resulted in more pine weevil damage. But, in contrast to other studies, the treatment with highest MJ volume $(\mathrm{M} 1+\mathrm{M} 2)$ did not receive the least amount of pine weevil damage. Altogether, this suggests that the timing of application may be relatively more important than recurrence in mediating effective protection against the pine weevil.

Additionally, our results also indicate that differential short and long term effects of MJ on seedling resistance can occur based on the timing of treatment. We observed that seedlings treated with MJ only before planting (M2) received similar or slightly more damage compared to other treatments during the first growing season. Yet, these effects appear to have been short-lasting as these seedlings received much more damage during the second season. In another conifer species, Sitka spruce (Picea sitchensis), it has been shown that the emission of terpenoids reached a peak within a week after MJ treatment; defensive compounds like monoterpenoids, sesquiterpenoids, and diterpenoids accumulated in the outer stem tissue and reached their maximum about 1 month after MJ treatment (Miller et al. 2005). The same study and another study on Norway spruce found that terpene synthesis was still active 1 month after MJ treatment (Martin 2002; Miller et al. 2005). Furthermore, it also has been shown that MJ-induced resistance against insects or pathogens can be maintained for more than a year (Zas et al. 2014; Erbilgin et al. 2006; Zhao et al. 2010).

Following MJ treatment, increased plant resistance to pests can occur through two mechanisms: prolonged up-regulation of inducible defenses, and priming of defense 
responses (Wilkinson et al. 2019). Prolonged upregulation occurs when defenses remain elevated for a long period following MJ application, and provide resistance against subsequent attack. For instance, formation of anatomical defenses, such as resin ducts in Norway spruce and leaf trichomes in tomato, can remain at greater densities for weeks and years respectively, following MJ treatment (Boughton et al. 2005; Krokene 2015). On the other hand, defense priming can occur when defenses are sensitized following an initial stimulus, such as MJ. This sensitization allows inducible defenses to be rapidly and more strongly activated upon subsequent attack (Pastor et al. 2013; Wilkinson et al. 2019). For Norway spruce, a recent study showed that MJ treatment enhanced resistance against bark beetle colonization in mature trees, and these effects were mediated through defense priming (Mageroy et al. 2020). Our study does not allow us to discern among the mechanisms underlying greater seedling resistance after MJ application. However, prolonged upregulation of inducible defenses can be costly, especially compared to defense priming (Wilkinson et al. 2019). Given the observed reductions in seedling growth following MJ treatment (discussed below), this could be a more plausible mechanism mediating short- and long-term effects. However, a threshold level of MJ might be required to achieve longer term effects as plants receiving the lowest dose (M2) were less protected compared to other treatments during the 2 year (Fig. 2e,f).

In line with other studies, we observed the well-established negative effect of MJ treatment on growth (Heijari et al. 2005; Gould et al. 2009). These effects became evident shortly after treatment for those seedlings of which MJ was applied before planting $(\mathrm{M} 1+\mathrm{M} 2$ and M2). The trade-off between growth and MJ-induced defense can also be seen in the longer term from the field growth results (Fig. 3c and 4e, $3 \mathrm{~d}$ and $4 \mathrm{f}$ ). However, these differences are expected to even out with time as MJ-treated seedlings recover from this temporary growth loss (Zas et al. 2014). In addition to these growth reductions, we interestingly found differences in mortality among MJ treatments and their possible causes. Mortality caused by the pine weevil did not differ significantly among MJ treatments, while mortality due to drought seems to be affected by MJ and age cohort. MJ treatment may have alleviated drought-related mortality for the S2015 cohort, but it appears to have exacerbated it for the younger cohort (Fig. 4). This is an important factor to consider when evaluating MJ-mediated plant protection. Previous studies have documented varying effects of MJ treatment on plant drought resistance and associated traits, such as root growth (Fedderwitz et al. 2019; Heijari et al. 2005; Moreira et al. 2012). Also, studies on cauliflower and soybean have shown that MJ application can alleviate drought stress (Wu et al. 2012; Mohamed and Latif 2017). However, its effects have been little studied in forest regeneration as drought is considered to cause less mortality compared to biotic factors. Further studies will be required to tease apart the contribution of MJ treatment relative to other factors (e.g., age) in mediating drought susceptibility or tolerance.

\section{Conclusion}

We conclude that timing of MJ treatment is relatively more important than recurrence of treatment or seedling age for effective protection against pine weevil damage. Our results showed that MJ treatment can be conducted the year previous to planting and can confer protection comparable to standard physical barriers. Thus, the use of MJ is compatible with nursery practices. Despite the known initial growth reductions and any potential side effects (e.g. drought tolerance/susceptibility), the positive effects of MJ in reducing pine 
weevil damage should not be overlooked. MJ could be a complementary approach to other current or novel approaches to safeguard plant health in a sustainable way. Future studies should address how timing, recurrence and actual MJ dosage received by the plants mediate induced resistance and the duration of its efficacy.

Acknowledgements Open access funding provided by Swedish University of Agricultural Sciences. We thank Claudia von Brömssen and Harimurti Buntaran for help with the statistical analysis, Claes Hellqvist and Staffan Karlsson for assisting with field work, Sunil Abeyasekera and Merlin Rensing for help both in lab and field. The study was supported by FORMAS Grant Number 942-2016-37.

Author contributions AP, CB, FF and HB conceived and designed the experiment. YC conducted the experiment, carried out the statistical analysis and led the writing with input from AP, CB and HB. All authors contributed to subsequent revisions of the manuscript.

Open Access This article is licensed under a Creative Commons Attribution 4.0 International License, which permits use, sharing, adaptation, distribution and reproduction in any medium or format, as long as you give appropriate credit to the original author(s) and the source, provide a link to the Creative Commons licence, and indicate if changes were made. The images or other third party material in this article are included in the article's Creative Commons licence, unless indicated otherwise in a credit line to the material. If material is not included in the article's Creative Commons licence and your intended use is not permitted by statutory regulation or exceeds the permitted use, you will need to obtain permission directly from the copyright holder. To view a copy of this licence, visit http://creativecommons.org/licenses/by/4.0/.

\section{References}

Bates D, Maechler M, Bolker B, Walker S (2015) Fitting linear mixed-effects models Using lme4. J Stat Softw 67(1):1-48. https://doi.org/10.18637/jss.v067.i01

Boughton AJ, Hoover K, Felton GW (2005) Methyl jasmonate application induces increased densities of glandular trichomes on tomato, Lycopersicon esculentum. J Chem Ecol 31(9):2211-2216

Choh Y, Ozawa R, Takabayashi J (2004) Effects of exogenous Jasmonic acid and benzo $(1,2,3)$ thiadiazole7-carbothioic acid S-methyl ester (BTH), a functional analogue of salicylic acid, on the egg production of a herbivorous mite Tetranychus urticae (Acari: Tetranychidae). Appl Entomol Zool 39(2):311-314

Erbilgin N, Krokene P, Christiansen E, Zeneli G, Gershenzon J (2006) Exogenous application of methyl jasmonate elicits defenses in Norway spruce (Picea abies) and reduces host colonization by the bark beetle Ips typographus. Oecologia 148(3):426-436

Eidmann HH, Nordenhem H, Weslien J (1996) Physical protection of conifer seedlings against pine weevil feeding. Scand J For Res 11(1-4):68-75

Fedderwitz F, Nordlander G, Ninkovic V, Björklund N (2015) Effects of jasmonate-induced resistance in conifer plants on the feeding behaviour of a bark-chewing insect, Hylobius abietis. J Pest Sci 89(1):97-105

Fedderwitz F, Björklund N, Anngren R, Lindström A, Nordlander G (2019) Can methyl jasmonate treatment of conifer seedlings be used as a tool to stop height growth in nursery forest trees? New Forest. https://doi.org/10.1007/s11056-019-09737-6

Fox J, Weisberg S (2011) An R companion to applied regression, 3rd edn. Sage, Thousand Oaks CA. https:// socialsciences.mcmaster.ca/jfox/Books/Companion/

Franceschi VR, Krokene P, Christiansen E, Krekling T (2005) Anatomical and chemical defenses of conifer bark against bark beetles and other pests. New Phytol 167(2):353-375

Gould N, Reglinski T, Spiers M, Taylor JT (2008) Physiological trade-offs associated with methyl jasmonate-induced resistance in Pinus radiata. Can J For Res 38(4):677-684

Gould N, Reglinski T, Northcott GL, Spiers M, Taylor JT (2009) Physiological and biochemical responses in Pinus radiata seedlings associated with methyl jasmonate-induced resistance to Diplodia pinea. Physiol Mol Plant Pathol 74(2):121-128

Hagner M, Jonsson C (1995) Survival after planting without soil preparation for pine and spruce seedlings protected from Hylobius abietis by physical and chemical shelters. Scand J For Res 10(1-4):225-234 
Heijari J, Nerg AM, Kainulainen P, Viiri H, Vuorinen M, Holopainen JK (2005) Application of methyl jasmonate reduces growth but increases chemical defence and resistance against Hylobius abietis in Scots pine seedlings. Entomol Exp Appl 115(1):117-124

Heijari J, Nerg AM, Kainulainen P, Vuorinen M, Holopainen JK (2008) Long-term effects of exogenous methyl jasmonate application on Scots pine (Pinus sylvestris) needle chemical defence and diprionid sawfly performance. Entomol Exp Appl 128(1):162-171

Huber DPW, Philippe RN, Madilao LL, Sturrock RN, Bohlmann J (2005) Changes in anatomy and terpene chemistry in roots of Douglas-fir seedlings following treatment with methyl jasmonate. Tree Physiol 25(8):1075-1083

Hudgins J, Christiansen E, Franceschi VR (2004) Induction of anatomically based defense responses in stems of diverse conifers by methyl jasmonate: a phylogenetic perspective. Tree Physiol 24(3):251-264

Kahl J, Siemens DH, Aerts RJ, Gäbler R, Kühnemann F, Preston CA, Baldwin IT (2000) Herbivore-induced ethylene suppresses a direct defense but not a putative indirect defense against an adapted herbivore. Planta 210(2):336-342

Karban R (2011) The ecology and evolution of induced resistance against herbivores. Funct Ecol 25(2):339-347

Koo AJK, Gao X, Daniel Jones A, Howe GA (2009) A rapid wound signal activates the systemic synthesis of bioactive jasmonates in Arabidopsis. Plant J 59(6):974-986

Krokene P (2015) Conifer defense and resistance to bark beetles. In Bark beetles (pp. 177-207). Academic Press

Långström B, Day K (2007) Damage, control and management of weevil pests, especially Hylobius abietis. Bark and Wood Boring Insects in Living Trees in Europe, a Synthesis. Springer, pp 415-444

Lenth R (2019). emmeans: Estimated marginal means, aka least-squares means. R package version 1.3.2. https://CRAN.R-project.org/package=emmeans

López-Villamor A, Carreño S, López-Goldar X, Suárez-Vidal E, Sampedro L, Nordlander G, Björklund N, Zas R (2019) Risk of damage by the pine weevil Hylobius abietis in southern Europe: effects of silvicultural and landscape factors. For Ecol Manage 444:290-298

Mageroy MH, Christiansen E, Långström B et al (2020) Priming of inducible defenses protects Norway spruce against tree-killing bark beetles. Plant Cell Environ 43:420-430. https://doi.org/10.1111/ pce. 13661

Martin D (2002) Methyl jasmonate induces traumatic resin ducts, terpenoid resin biosynthesis, and terpenoid accumulation in developing xylem of Norway spruce stems. Plant Physiol 129(3):1003-1018

Matyjaszczyk E, Karmilowicz E, Skrzecz I (2019) How European Union accession and implementation of obligatory integrated pest management influenced forest protection against harmful insects: a case study from Poland. For Ecol Manage 433:146-152

McConn M, Creelman RA, Bell E, Mullet JE, Browse J (1997) Jasmonate is essential for insect defense in Arabidopsis. Proc Natl Acad Sci 94(10):5473-5477

Miller B, Madilao LL, Ralph S, Bohlmann J (2005) Insect-induced conifer defense. White pine weevil and methyl jasmonate induce traumatic resinosis, de novo formed volatile emissions, and accumulation of terpenoid synthase and putative octadecanoid pathway transcripts in Sitka spruce. Plant Physiol 137(1):369-382

Mohamed HI, Latif HH (2017) Improvement of drought tolerance of soybean plants by using methyl jasmonate. Physiol Molecul Biol Plants 23(3):545-556

Moreira X, Sampedro L, Zas R (2009) Defensive responses of Pinus pinaster seedlings to exogenous application of methyl jasmonate: concentration effect and systemic response. Environ Exp Bot 67(1):94-100

Moreira X, Zas R, Sampedro L (2012) Genetic variation and phenotypic plasticity of nutrient re-allocation and increased fine root production as putative tolerance mechanisms inducible by methyl jasmonate in pine trees. J Ecol 100(3):810-820

Nordlander G, Nordenhem H, Hellqvist C (2009) A flexible sand coating (Conniflex) for the protection of conifer seedlings against damage by the pine weevil Hylobius abietis. Agric For Entomol 11(1):91-100

Nordlander G, Hellqvist C, Johansson K, Nordenhem H (2011) Regeneration of European boreal forests: effectiveness of measures against seedling mortality caused by the pine weevil Hylobius abietis. For Ecol Manage 262(12):2354-2363

Omer AD, Thaler JS, Granett J, Karban R (2000) Jasmonic acid induced resistance in grapevines to a root and leaf feeder. J Econ Entomol 93(3):840-845

Örlander G, Nilsson U (1999) Effect of reforestation methods on pine weevil (Hylobius abietis) damage and seedling survival. Scand J For Res 14(4):341-354

Pastor V, Luna E, Mauch-Mani B, Ton J, Flors V (2013) Primed plants do not forget. Environ Exp Bot $94: 46-56$ 
R Core Team (2018) R: A language and environment for statistical computing. R Foundation for Statistical Computing, Vienna, Austria. https://www.R-project.org/

RStudio Team (2016) RStudio: Integrated development for R. RStudio, Inc., Boston, MA URL http:// www.rstudio.com/

Sampedro L, Moreira X, Zas R (2010) Resistance and response of Pinus pinaster seedlings to Hylobius abietis after induction with methyl jasmonate. Plant Ecol 212(3):397-401

Selig P, Keough S, Nalam VJ, Nachappa P (2016) Jasmonate-dependent plant defenses mediate soybean thrips and soybean aphid performance on soybean. Arthropod-Plant Interactions 10(4):273-282

Stella de Freitas TF, Stout MJ, Sant'Ana J (2019) Effects of exogenous methyl jasmonate and salicylic acid on rice resistance to Oebalus pugnax. Pest Manag Sci 75(3):744-752

Stenberg JA (2017) A conceptual framework for integrated pest management. Trends Plant Sci 22(9):759-769

Thaler JS, Stout MJ, Karban R, Duffey SS (2001) Jasmonate-mediated induced plant resistance affects a community of herbivores. Ecological Entomology 26(3):312-324

Venables WN, Ripley BD (2002) Modern applied statistics with S, 4th edn. Springer, New York. ISBN 0-387-95457-0

Von Sydow F (1997) Abundance of pine weevils (Hylobius abietis) and damage to conifer seedlings in relation to silvicultural practices. Scand J For Res 12(2):157-167

Wallertz K, Björklund N, Hjelm K, Petersson M, Sundblad LG (2018) Comparison of different site preparation techniques: quality of planting spots, seedling growth and pine weevil damage. New Forests (Dordr) 49(6):705-722

Warabieda W, Miszczak A, Olszak R (2005) The influence of methyl jasmonate (JA-Me) and B-glucosidase on induction of resistance mechanisms of strawberry against two-spotted spider mite (Tetranychus urticae Koch.). Commun Agricult Appl Biol Sci 70(4):829-836

Wickham H (2016) ggplot2: Elegant graphics for data analysis. Springer, New York

Wilkinson SW, Magerøy MH, Sánchez AL, Smith LM, Furci L, Cotton TEA, Krokene P, Ton J (2019) Surviving in a hostile world: plant strategies to resist pests and diseases. Annu Rev Phytopathol 57(1):505-529

Wu H, Wu X, Li Z, Duan L, Zhang M (2012) Physiological evaluation of drought stress tolerance and recovery in cauliflower (Brassica oleracea L.) seedlings treated with methyl lasmonate and coronatine. J Plant Growth Regulation 31(1):113-123

Yu X, Zhang W, Zhang Y, Zhang X, Lang D, Zhang X (2019) The roles of methyl jasmonate to stress in plants. Funct Plant Biol 46(3):197

Zas R, Björklund N, Nordlander G, Cendán C, Hellqvist C, Sampedro L (2014) Exploiting jasmonateinduced responses for field protection of conifer seedlings against a major forest pest, Hylobius abietis. For Ecol Manage 313:212-223

Zeneli G, Krokene P, Christiansen E, Krekling T, Gershenzon J (2006) Methyl jasmonate treatment of mature Norway spruce (Picea abies) trees increases the accumulation of terpenoid resin components and protects against infection by Ceratocystis polonica, a bark beetle-associated fungus. Tree Physiol 26(8):977-988

Zhao T, Krokene P, Bjorklund N, Langstrom B, Solheim H, Christiansen E, Borg-Karlson AK (2010) The influence of Ceratocystis polonica inoculation and methyl jasmonate application on terpene chemistry of Norway spruce, Picea abies. Phytochemistry 71(11-12):1332-1341

Publisher's Note Springer Nature remains neutral with regard to jurisdictional claims in published maps and institutional affiliations. 